\title{
The Bearing Capacity of Circular Footings in Sand: Comparison between Model Tests and Numerical Simulations Based on a Nonlinear Mohr Failure Envelope
}

\author{
Sven Krabbenhoft, ${ }^{1}$ Johan Clausen, ${ }^{2}$ and Lars Damkilde ${ }^{1}$ \\ ${ }^{1}$ Esbjerg Institute of Technology, Aalborg University, Niels Bohrs Vej 8, 6700 Esbjerg, Denmark \\ ${ }^{2}$ Department of Civil Engineering, Aalborg University, Sohngaardholmsvej 57, 9000 Aalborg, Denmark
}

Correspondence should be addressed to Sven Krabbenhoft, skr@civil.aau.dk

Received 7 September 2011; Revised 14 November 2011; Accepted 16 November 2011

Academic Editor: Jianqiao Ye

Copyright ( $\odot 2012$ Sven Krabbenhoft et al. This is an open access article distributed under the Creative Commons Attribution License, which permits unrestricted use, distribution, and reproduction in any medium, provided the original work is properly cited.

\begin{abstract}
This paper presents the results of a series of triaxial tests with dry sand at confining pressures varying from $1.5 \mathrm{kPa}$ to $100 \mathrm{kPa}$ at relative densities of $0.20,0.59$, and 0.84 . The results, which are in reasonable accordance with an equation given by Bolton, show that the friction angle is strongly dependent on the stress level and on the basis of the test results, a nonlinear Mohr failure criterion has been proposed. This yield criterion has been implemented in a finite element program and an analysis of the bearing capacity of a circular shaped model foundation, diameter $100 \mathrm{~mm}$, has been conducted. Comparisons have been made with results from $1 \mathrm{~g}$ model scale tests with a foundation of similar size and a good agreement between numerical results and test results has been found.
\end{abstract}

\section{Introduction}

In conventional design of shallow foundations, earth retaining structures, slopes, and the friction angle of sand are regarded as a constant, being primarily dependent on the relative density of the material. Experimental work (e.g., [1, 2 ]) has shown that the friction angle is also dependent upon the confining pressure; i.e., the stress level. In cases where the mean effective stress is above $150 \mathrm{kPa}$ the equation developed by Bolton [3] for a sand with a given mineralogy takes this dependency into account in a simple but sufficiently accurate way, but for the lower stress levels typically encountered in connection with simple model tests in a soil laboratory higher accuracy is desirable. This is due to the strong dependency of the bearing capacity factors and soil pressure coefficients on the angle of friction. Also in such cases where high accuracy is needed, grading and grain shape, as shown by Fukushima and Tatsuoka [2], may have an effect on the magnitude of the angle of friction.

One of the main effects in geotechnical structures always stems from body forces and therefore the stress level in simple laboratory experiments is always much lower than the stress level in real life. For this reason very often, one has to accept large discrepancies between results from these laboratory tests and the equivalent conventional geotechnical calculations. As examples of this Hansen [4] and Zadroga [5] reported that the bearing capacities of model foundations found in tests are considerably higher than the ones found in calculations.

When the friction angle is constant and the response is considered linearly elastic perfectly plastic, the material model is termed Mohr-Coulomb, which is the one used in standard geotechnical designs. For this reason a lot of experience has been gathered regarding the parameters used in the model (Young's modulus E, Poisson's ratio $v$ and the friction angle, $\varphi$ ) and the calculations involving this model. One of the great virtues of the model is the possibility to use hand calculation methods in many practical cases.

The Mohr-Coulomb model predicts a linear relation between the normal stress acting on a slip surface and strength. Experiments, however, have shown that this is not true. When carried out at low stress levels in the 
laboratory model experiments predict a far higher friction angle compared to the one obtained at realistic stress levels.

To allow for the nonlinear dependency of the strength on the stress level, physical modelling in connection with centrifuge tests has become widespread over the past thirty to forty years. Also over these years, there has been a great increase in the computational power available, due to bigger and cheaper computers combined with very efficient modelling methods such as the finite element method, and it seems obvious that everyday design of soil structures could now be based on a more advanced model than the MohrCoulomb model. In comparison rock mass structures are now routinely being designed using the nonlinear HoekBrown criterion [6].

The main aims of the work described in the present paper are threefold. Firstly, it is to determine a simple failure envelope of the type of sand used for simple model tests in the geotechnical laboratory of Esbjerg Institute of Technology in Denmark. Secondly, the model is implemented in an elastoplastic finite element code in order to carry out bearing capacity calculations. Thirdly, these bearing capacity calculations are compared with model tests carried out in the laboratory.

Another purpose of the paper is to advocate the need for a slightly more complicated failure criterion in practical calculations, compared to conventional use of the constant MohrCoulomb friction angle. With the modern day availability of inhouse and commercial numerical computations codes, it should now be tractable to carry out routine geotechnical design with more realistic material models. The purpose of this paper is not to propose an all-encompassing constitutive model as it is for example seen in [7-9], as these advanced models are still considered too advanced for everyday use, both with regards to parameter determination and numerical computations.

As a validation of the model, results from numerical simulations of the bearing capacity of a circular model footing are compared with the results of simple model tests carried out in the geotechnical laboratory of Esbjerg Institute of Technology in Denmark. The footing has a diameter of $10 \mathrm{~cm}$ and tests are carried out on sand at different relative densities. The numerical simulations are based on a nonlinear Mohr failure envelope of which the parameters have been determined through triaxial tests.

\section{Type of Sand Tested}

The sand used in the experiments is Esbjerg sand, which is an alluvial, medium grained sized quartz sand of subangular shape with the characteristics given in Table 1 . To find the strength properties of the sand, triaxial tests were carried out.

\section{Triaxial Tests, Specimen Preparation, and Testing Equipment}

The triaxial tests were carried out with dry sand in a triaxial testing apparatus. The confining pressure was applied by lowering the air pressure inside the test specimen. The
TABle 1: Properties of Esbjerg sand.

\begin{tabular}{lc}
\hline Parameter & Value \\
\hline$D_{10}(\mathrm{~mm})$ & 0.25 \\
$D_{60}(\mathrm{~mm})$ & 0.58 \\
$C_{u}=D_{60} / D_{10}$ & 2.32 \\
$D_{50}(\mathrm{~mm})$ & 0.50 \\
Specific density & 2.621 \\
Maximum void ratio $\mathrm{e}_{\max }$ & 0.733 \\
Minimum void ratio $\mathrm{e}_{\min }$ & 0.449 \\
Relative density in tests & $0.20,0.59,0.84$ \\
Dry unit weight in tests $\left(\mathrm{kN} / \mathrm{m}^{3}\right)$ & 15.6416 .7417 .54 \\
\hline
\end{tabular}

diameter and height of the test specimens were $70 \mathrm{~mm}$. A schematic drawing of the load test set up is shown in Figure 1(a).

The deviatoric stress was applied using a hydraulic cylinder operated with a hand pump, and the force was recorded by means of an electronic load cell which was placed inside the cell to obtain as accurate values as possible. The confining pressure was provided by a vacuum pump connected to the specimen through the loading plates at either end of the specimen and the amount of vacuum was controlled by a valve operated by hand and recorded using a pressure transducer. The vertical displacements were measured by means of two displacement transducers mounted outside the cell and the displacements were taken as average values of these two transducer readings. The volumetric changes of the specimens were recorded by a displacement transducer which could register the movements of the water table in a burette connected to the water filled cell. The diameter of both loading plates is $90 \mathrm{~mm}$, and the thickness is $50 \mathrm{~mm}$. The membrane, made from $0.30 \mathrm{~mm}$ rubber, was fastened to the base plate and sealed with an O-ring and held by vacuum to the inner surface of a cylindrical split mould. Both the bases made from aluminium and the nylon cap were provided with 2 layers of lubricated $0.30 \mathrm{~mm}$ latex sheets.

The specimens were prepared by preweighing the specific amount of sand to obtain the desired relative density and the sand was placed through a funnel in an appropriate number of steps. Between each of the steps the sand was compacted by tamping to obtain the desired density. For the loose samples (relative density, $D_{r}=0.20$ ), no compacting at all was necessary; for the medium dense samples $\left(D_{r}=0.59\right)$, the sand was placed in three steps and for the dense samples, $\left(D_{r}=0.84\right)$ the sand was placed in five steps. When the surface of the sand had been scraped carefully with a metal plate, the cap was placed and the upper part of the membrane was sealed to the cap with an O-ring. A vacuum of approximately $20 \mathrm{kPa}$ was applied and the split mould was removed and the specimen was placed in the cell. Following this, the load cell was put in position, the lid of the cell, and the burette was placed and the cell was filled with water, until the water in the burette reached the desired level which was $0.53 \mathrm{~m}$ above the center of the specimen. In the tests with a confining pressure of $1.5 \mathrm{kPa}$, the cell was not completely 


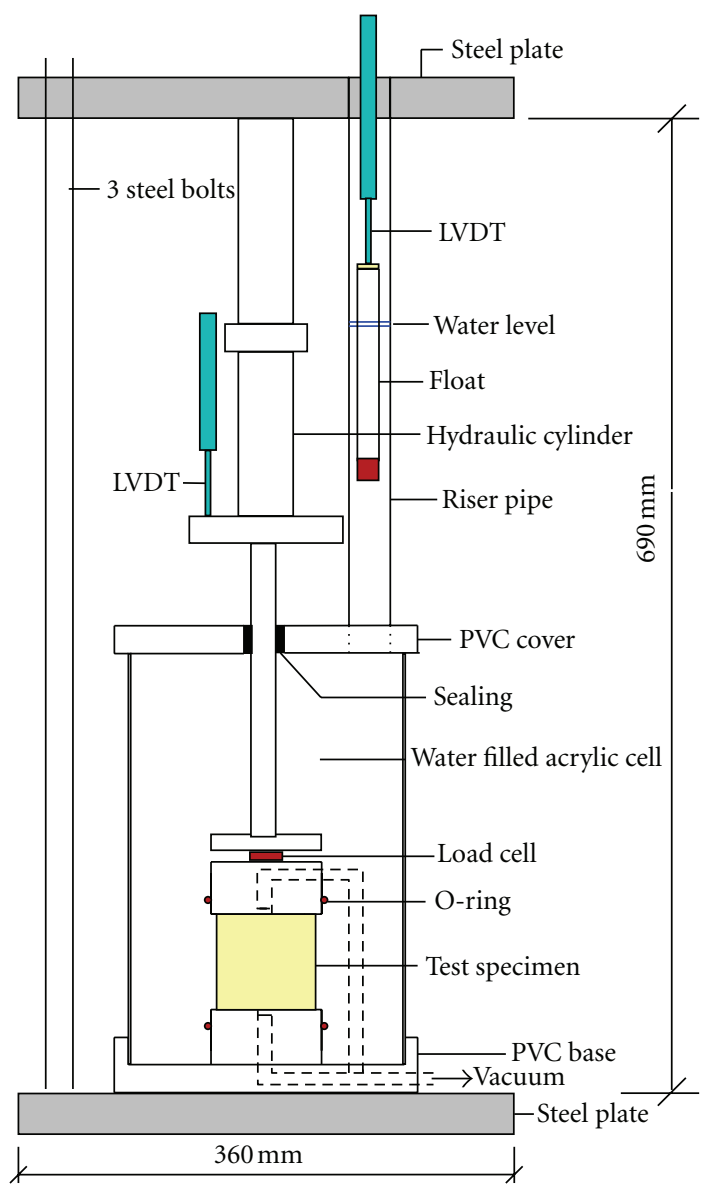

(a)

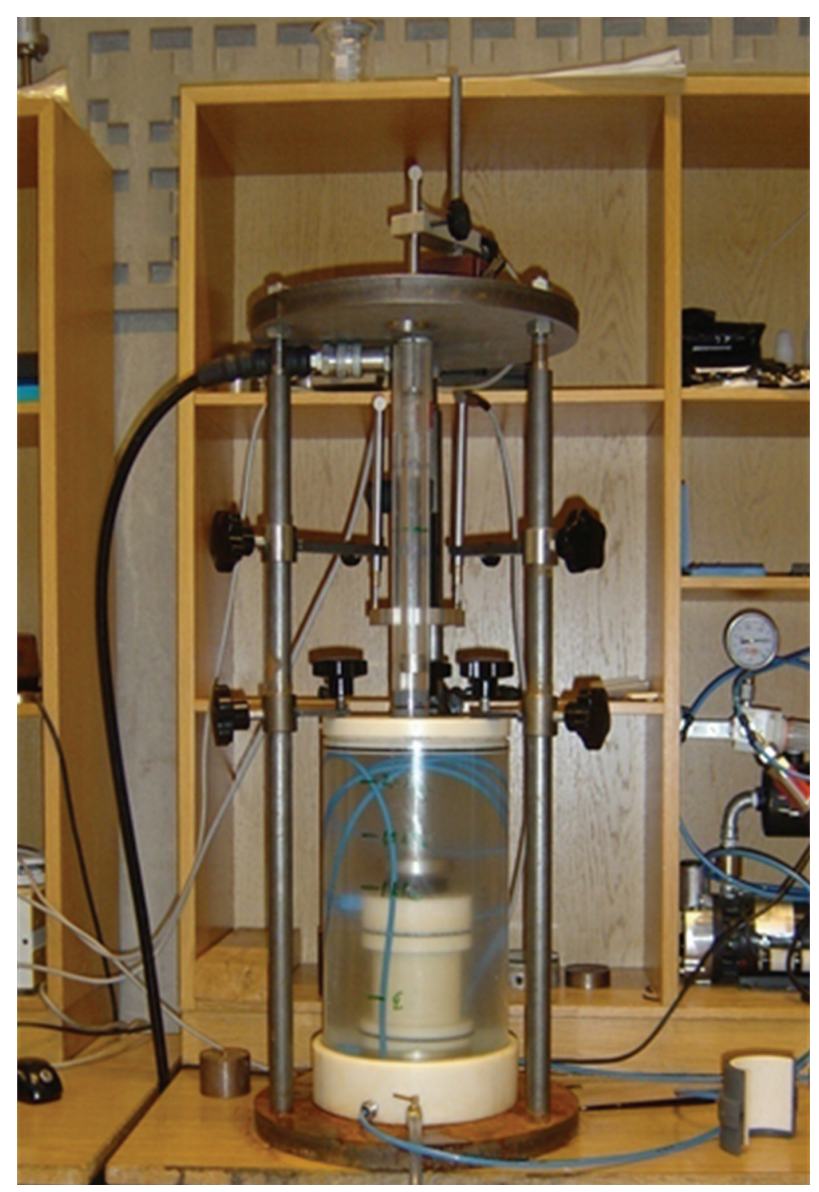

(b)

FIGURE 1: Schematic drawing and photograph of the triaxial test setup.

filled with water, so it was not possible to record the volume changes.

After the three displacement transducers and the hydraulic cylinder had been put in position, the vacuum was removed and all transducers were zeroed. Hereafter, the specimen was isotropically consolidated by application of vacuum to the desired level of the effective confining pressure and after a few minutes when it was clear from the transducer readings, that there were no further volume changes, all transducers were zeroed again and the load was applied, so as to produce a rate of displacement of approximately $5 \mathrm{~mm}$ pr minute. For the two lowest values of the confining pressure the confining was provided solely by the water pressure.

The additional radial stress due to the stiffness of the membrane has been taken account by the equation [2]:

$$
\Delta \sigma_{r}=\frac{2 E_{\mathrm{m}} t \varepsilon_{\theta}}{d}
$$

where $E_{\mathrm{m}}=$ modulus of elasticity of the membrane (1.7 MPa), $t=$ thickness of membrane $(0.30 \mathrm{~mm}), \varepsilon_{\theta}=$ tangential strain of the membrane $=$ the radial strain of the membrane, and $d=$ diameter of sample (which varies during the test and $=70 \mathrm{~mm}$ at the beginning).
Corrections to the deviatoric stress due to the increase in the cross-sectional area of the sample during testing have been made by computing the deviatoric stress from the equation:

$$
\Delta \sigma_{a}=\frac{P}{A_{0}} \frac{1-\varepsilon_{a}}{1-\varepsilon_{v}},
$$

where $P$ is the applied load, $A_{0}$ is the initial cross sectional area of the sample, and $\varepsilon_{a}$ is the axial strain and $\varepsilon_{v}$ the volumetric strain. For the tests carried out at a confining stress of $1.5 \mathrm{kPa}$ it was not possible to measure the volumetric strain and instead an estimated value for $\mathcal{E}_{v}$ has been used.

\section{Testing Programme and Results}

Triaxial tests were carried out for relative densities of 0.20 , 0.59 , and 0.84 and for each relative density, the following values of the initial confining stress were applied: $1.5 \mathrm{kPa}$, $5.3 \mathrm{kPa}, 20 \mathrm{kPa}, 50 \mathrm{kPa}$, and $100 \mathrm{kPa}$. The results are shown in Figures 2, 3, and 4 and summarized in Table 2. The peak friction angles in column 3 are calculated according to the equation:

$$
\left(\frac{\sigma_{1}}{\sigma_{3}}\right)_{\max }=\frac{1+\sin \varphi_{\text {peak }}}{1-\sin \varphi_{\text {peak }}} .
$$




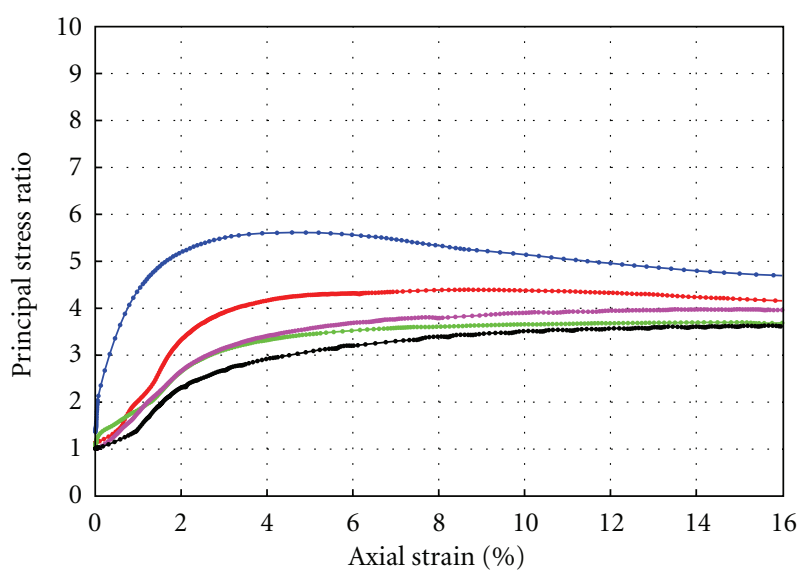
- Confining pressure $1.5 \mathrm{kPa} \longrightarrow$ Confining pressure $50 \mathrm{kPa}$
- Confining pressure $5.3 \mathrm{kPa} \longrightarrow$ Confining pressure $100 \mathrm{kPa}$
- Confining pressure $20 \mathrm{kPa}$

(a)

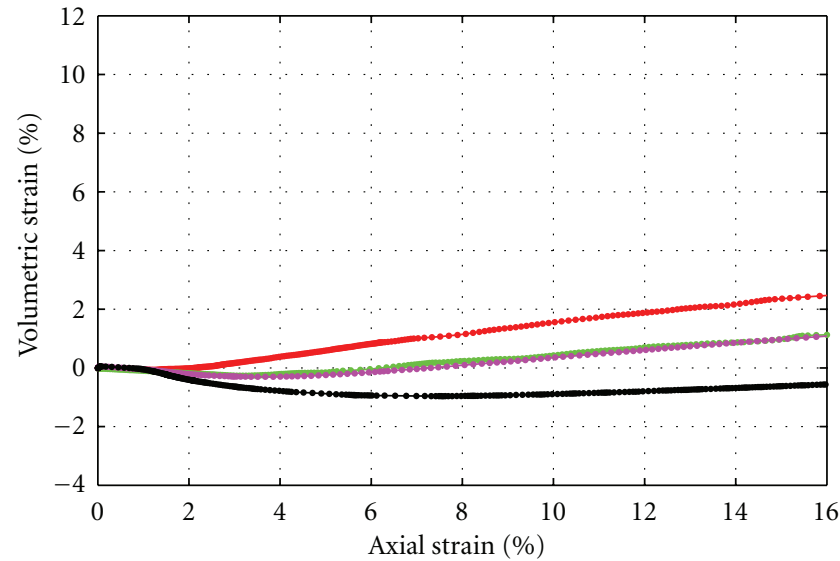

$\rightarrow$ Confining pressure $5.3 \mathrm{kPa} \rightarrow$ Confining pressure $50 \mathrm{kPa}$

$\rightarrow$ Confining pressure $20 \mathrm{kPa} \rightarrow$ Confining pressure $100 \mathrm{kPa}$

(b)

FIgURE 2: Test results for Esbjerg sand- $D_{r}=0.20$.

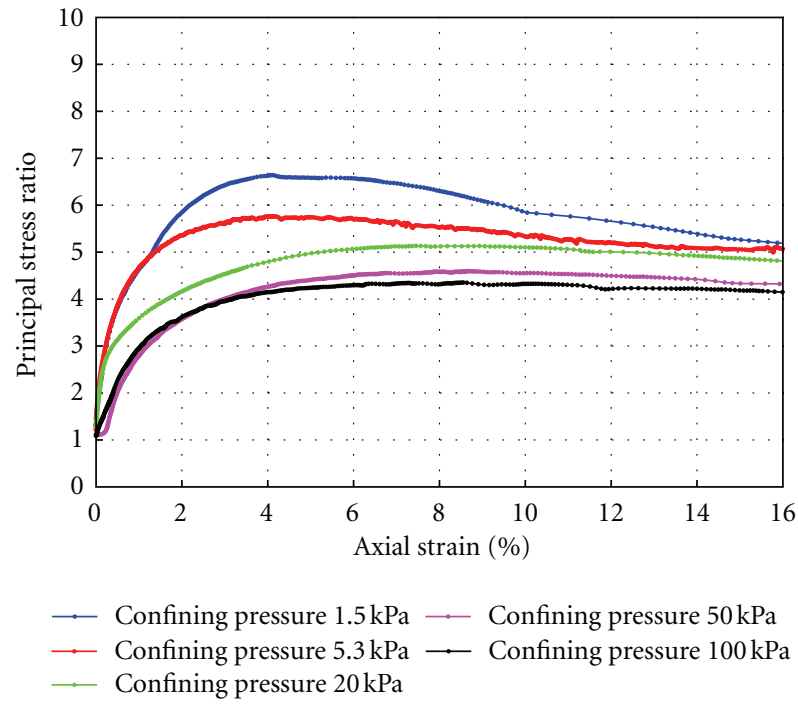

(a)

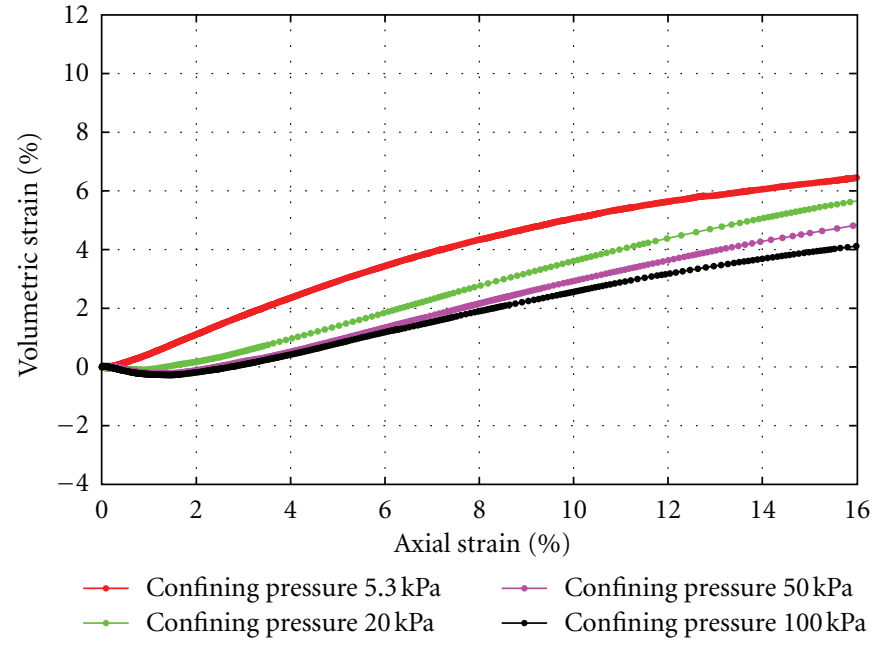

(b)

Figure 3: Test results for Esbjerg sand- $D_{r}=0.59$.

In this equation, which is derived from the linear MohrCoulomb failure criterion, $\sigma_{3}$ is the confining pressure, $\sigma_{1}$ is the maximum stress, and $\varphi_{\text {peak }}$ is the peak friction angle, which varies with the confining pressure $\sigma_{3}$ and because of this becomes a secant angle.

The angle of dilation $\psi$ is defined in plane strain by the equation originally suggested by Hansen [4]:

$$
\sin \left(\psi_{\max }\right)=\left(-\frac{d \varepsilon_{v}}{\delta \gamma_{\max }}\right)_{\text {max }}=\left(-\frac{d \varepsilon_{1}+d \varepsilon_{3}}{d \varepsilon_{1}-d \varepsilon_{3}}\right)_{\max } .
$$

In triaxial compression at least two different definitions exist (see e.g. $[10,11])$ :

$$
\begin{aligned}
& \sin \psi_{\text {max }}=\left(-\frac{d \varepsilon_{1}+2 d \varepsilon_{3}}{d \varepsilon_{1}-d \varepsilon_{3}}\right)_{\text {max }}, \\
& \sin \psi_{\text {max }}=\left(-\frac{d \varepsilon_{1}+2 d \varepsilon_{3}}{d \varepsilon_{1}-2 d \varepsilon_{3}}\right)_{\text {max }} .
\end{aligned}
$$

The commonly used numerical code Plaxis suggest $\psi$ be estimated from (6) and also this definition has been used in the present study. 


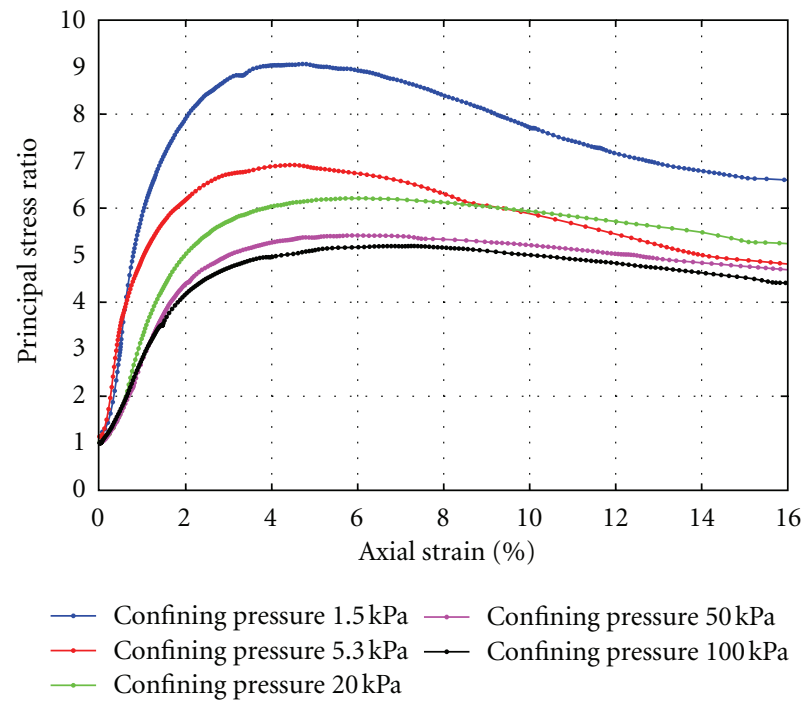

(a)

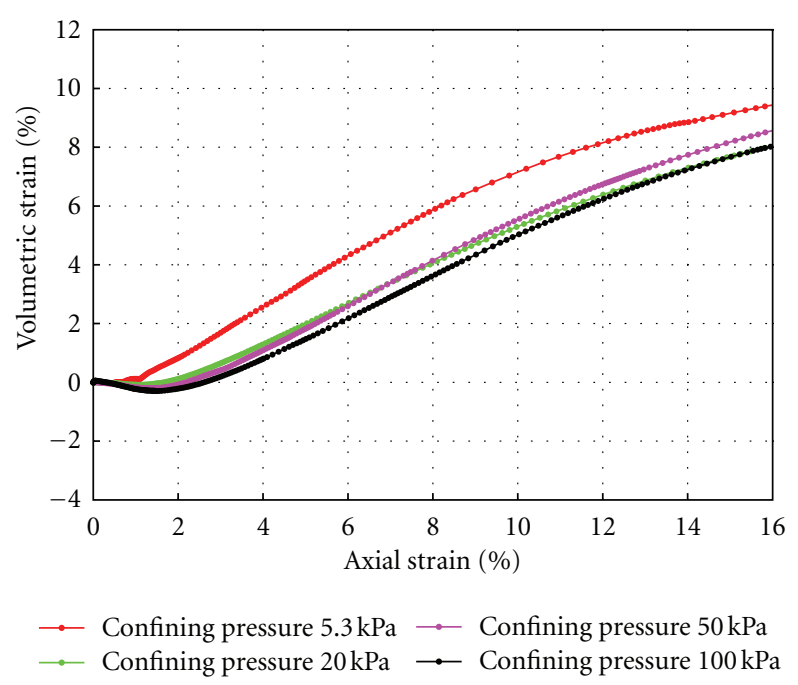

(b)

FIgURE 4: Test results for Esbjerg sand- $D_{r}=0.84$.

It is a well-known fact that dilation plays an important role in the study of the strength of soil [12] and also in general, the angle of dilation is considerably smaller than the angle of friction. Collapse loads for materials with a nonassociated flow rule are smaller than those obtained for the same material when an associated flow rule is assumed. From experience it is known that in cases where there is a substantial difference between $\varphi$ and $\psi$ numerical problems arise in the solution of nonlinear finite element equations. To overcome these difficulties [13] proposed using a modified friction angle making it possible to deal with the material, as if it was obeying the normality condition. According to [14], the modified friction angle $\varphi_{\text {mod }}$ can be found from the equation:

$$
\tan \varphi_{\text {mod }}=\frac{\sin \varphi \cos \psi}{1-\sin \varphi \sin \psi}
$$

The values of $\varphi$ and $\psi$ on the right hand side of the equation are given in column 3 and 4 in Table 2 and the values of $\varphi_{\bmod }$ are given in column 5 in Table 2.

The test results have been compared with values found with the Bolton equation [3] for triaxial compression:

$$
\varphi_{\text {peak }}=\varphi_{\mathrm{cv}}+3\left(D_{r}\left(Q-\ln p^{\prime}\right)-R\right) .
$$

In this equation, $\varphi_{\text {peak }}$ is the friction angle at peak, $\varphi_{\mathrm{cv}}$ is the friction angle at constant volume, $D_{\mathrm{r}}$ the relative density, and $Q$ and $R$ are parameters which depend on the mineralogy of the grain material. For the quartz sand used in this study $Q=$ 10 and $R=1$ are used. The mean normal stress is denoted $p^{\prime}$ and can be found as:

$$
p^{\prime}=\frac{1}{3}\left(\sigma_{1}+2 \sigma_{3}\right)
$$

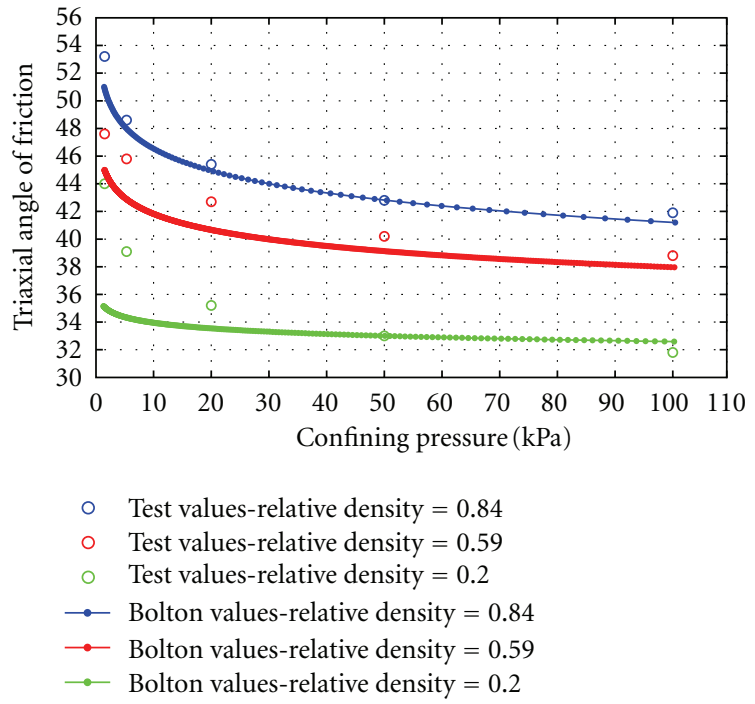

Figure 5: Friction angles for Esbjerg Sand.

under triaxial conditions. Inserting (3) and (9) in (8) and solving for $\sigma_{3}$ yields the following equation:

$$
\sigma_{3}=\frac{3\left(1-\sin \varphi_{\text {peak }}\right)}{3-\sin \varphi_{\text {peak }}} \exp \left(\frac{\varphi_{\mathrm{cv}}-\varphi_{\text {peak }}+3 D_{r} Q-3 R}{3 D_{r}}\right) .
$$

The variation of the friction angle with confining pressure found in the triaxial tests is shown in Figure 5 together with the values of the friction angle according to (10). The value of $\varphi_{\mathrm{cv}}$ has been found according to the method proposed by Cornforth [15] and the average of ten tests yielded a value of $32.7^{\circ}$. 


\section{Discussion of Test Results}

The tests have shown that the angle of friction varies significantly with the confining pressure and that the greater the confining stress, the smaller the angle of friction. This variation is greater for smaller values of the confining stress. The values of the friction angle according to Bolton's equation are, in general, smaller than the test values. These differences are greater for smaller values of the relative density and the confining pressure and this tendency has been confirmed by the tests carried out by Ponce and Bell, while the tests by Fukushima and Tatsouka have shown no variation of the friction angle with confining pressures below $50 \mathrm{kPa}$. From Figures 2, 3, and 4, it can be seen that the sand exhibits strain softening and increases its volume in almost all the tests and this characteristic is more pronounced for the larger relative densities and the smaller confining pressures.

\section{The Nonlinear Failure Envelope}

The linear Mohr-Coulomb failure envelope is given by the equation:

$$
\begin{aligned}
\sigma_{1} & =\frac{1+\sin \varphi}{1-\sin \varphi} \sigma_{3}+2 c \sqrt{\frac{1+\sin \varphi}{1-\sin \varphi}} \\
& =k \sigma_{3}+\sigma_{c},
\end{aligned}
$$

where $c$ is the cohesion, $k$ and $\sigma_{c}$ are a friction parameter and the uniaxial compression strength, respectively, given by:

$$
k=\frac{1+\sin \varphi}{1-\sin \varphi}, \quad \sigma_{c}=2 c \sqrt{\frac{1+\sin \varphi}{1-\sin \varphi}}=2 c \sqrt{k} .
$$

For a purely frictional material, such as sand, we have $c=$ $\sigma_{c}=0$.

As discussed above the linear Mohr-Coulomb envelope is a poor fit to the test results at small stress levels where the dependency of $\varphi$ on the stress level is more pronounced.

Several authors have suggested yield functions that take the $\varphi$-dependency of stress level into account, for example: De Mello [16], Charles and Watts [17], Collins et al. [18], Simonini [19], Baker [20], and Baker and Awidat [21]. In the present study, it has been found appropriate to use an expression of the form:

$$
\sigma_{1}=k_{0} \sigma_{3}+s_{c 0}\left(1-\exp \left(-a \frac{\sigma_{3}}{s_{c 0}}\right)\right),
$$

which is a curved envelope that passes through the origin and tends toward the asymptote:

$$
\sigma_{1}=k_{0} \sigma_{3}+s_{c 0} \quad \text { for } \sigma_{3} \longrightarrow \infty .
$$

The parameters $k_{0}$ and $s_{c 0}$ define the asymptote slope and intersection with the $\sigma_{1}$ axis, respectively, and $a$ adjusts the curvature. The parameters $k_{0}, s_{c 0}$, and $a$ are determined from nonlinear regression analysis based on the modified friction angle given in Table 2, column 5, for the three relative densities of the experiments. The values are given in Table 3 . In Figure 6, the nonlinear failure envelope, modified test results, and the linear asymptote for $D_{r}=0.84$ are shown.

\section{Finite Element Calculations}

The failure criterion of (13) is implemented into an in house finite element code using the software package Matlab. The material is considered as a linearly elastic - perfectly plastic material and for the elastic modulus $E$ and the poisson ratio $v$ values of $10 \mathrm{MPa}$ and 0.30 were used. The main aim of the calculations is to determine the failure loads, which is independent of the chosen values of $\mathrm{E}$ and $\nu$. For the plastic stress update, a method analogous to the one for a HoekBrown material is employed, see Clausen and Damkilde [22]. The footing is assumed to be rigid and perfectly rough. A downwards displacement is applied to the footing nodes in steps until the failure load is reached. The footing load is then calculated by summing up the vertical reaction forces of the footing nodes and dividing with the footing area.

As pointed out by Siddiquee et al. [23] and Tatsuoka et al. [24], there may be some effect on the bearing capacity from strain softening causing progressive failure, anisotropy of the sand, and the mean particle size $D_{50}$. The model applied in this study is not able to take these effects into account. As to strain softening, it can be said that progressive failure is not as pronounced with axisymmetric footings as with strip footings, because of the tougher behavior of the sand with the former. From Figures 3 and 4, it can be seen that the strength reduction due to softening becomes of some importance only at an axial strain in the region of $6-8 \%$, and therefore there may be some justification in considering softening and hence progressive failure being of minor importance. As to anisotropy, according to Kimura et al. [25], the effect of anisotropy is more marked for the stiffness than for the bearing capacity, and therefore it has not been considered. Kusakabe [26] found the value of $D_{50} / B=1 / 100$ to be the limit, where the effect of the particle size on the bearing capacity becomes less marked and as the sand used in the tests has a value of $D_{50} / B=0.5 / 100=1 / 200$ being well below the limit, this effect was ignored.

\section{Tests with Model Foundations}

To verify the validity of the proposed nonlinear yield function, $1 \mathrm{~g}$ model tests in axisymmetric conditions were carried out. The sand used for the tests was the Esbjerg sand described above, and the tests were conducted at relative densities $D_{r}=0.59$ and $D_{r}=0.84$. A circular footing with diameter $B=10 \mathrm{~cm}$ was used. Its base was covered with a rough material, to make it perfectly rough. In all tests, the footing was resting at the surface, resulting in no overburden pressure. The dry sand was placed in a cylindrical plastic container with a diameter $=55 \mathrm{~cm}$ and height $=35 \mathrm{~cm}$ in layers of approximately $5 \mathrm{~cm}$. Each layer was tamped a certain number of times to give the desired relative density and the total volume of sand was weighed. To minimize the effect of the sand not having a completely uniform density throughout the container, ten identical tests at each relative density were performed.

The load was applied to the footing by a hydraulic jack mounted on a steel beam, which was fastened to the concrete floor in the lab using $28 \mathrm{~mm}$ threaded steel bars. During 
TABLe 2: Test results for Esbjerg sand, * estimated value.

\begin{tabular}{lcccc}
\hline $\begin{array}{l}\text { Confining pressure } \sigma_{3} \\
{[\mathrm{kPa}]}\end{array}$ & Relative density $D_{r}$ & $\begin{array}{c}\text { Peak angle of friction } \\
\varphi_{\text {peak }}[\text { deg.] }\end{array}$ & $\begin{array}{c}\text { Angle of dilation } \psi_{\max } \\
\text { [deg.] }\end{array}$ & $\begin{array}{c}\text { Modified peak angle of } \\
\text { friction } \varphi_{\bmod }[\text { deg.] }\end{array}$ \\
\hline 1.5 & 0.20 & 44.3 & $7.0^{*}$ & 37.2 \\
5.3 & 0.20 & 39.0 & 5.2 & 33.6 \\
20 & 0.20 & 35.2 & 3.5 & 30.8 \\
50 & 0.20 & 33.0 & 2.7 & 29.2 \\
100 & 0.20 & 31.8 & 1.5 & 28.1 \\
1.5 & 0.59 & 47.6 & $17.0^{*}$ & 42.0 \\
5.3 & 0.59 & 44.8 & 13.4 & 39.3 \\
20 & 0.59 & 42.4 & 10.8 & 37.2 \\
50 & 0.59 & 40.0 & 11.0 & 35.7 \\
100 & 0.59 & 38.9 & 9.4 & 34.6 \\
1.5 & 0.84 & 53.3 & $23.0^{*}$ & 47.0 \\
5.3 & 0.84 & 48.6 & 18.3 & 43.0 \\
20 & 0.84 & 46.1 & 14.8 & 40.1 \\
50 & 42.4 & 15.5 & 38.7 \\
100 & 0.84 & 41.3 & 13.7 & 37.6 \\
\hline
\end{tabular}

TABLE 3: Parameters in nonlinear yield function.

\begin{tabular}{lccc}
\hline Relative density & $k_{0}$ & $s_{c 0}[\mathrm{kPa}]$ & $a$ \\
\hline 0.20 & 2.6613 & 12.0619 & 0.9082 \\
0.59 & 3.4409 & 18.8313 & 1.0887 \\
0.84 & 3.9355 & 19.7073 & 1.4330 \\
\hline
\end{tabular}

the test, the load was recorded using a load transducer, HBM S9, and the vertical displacements were recorded by a displacement transducer HBM WA/50 mm. Both load and displacement transducers were calibrated before the tests. The load was raised continuously, and the rate of displacement was app. $5 \mathrm{~mm} /$ minute. The test values were recorded by means of a datalogger Spider 8 from HBM. A photo of the load test setup is shown in Figure 7.

Bulging was observed both for the medium dense and the dense sand. The bulge never reached the edge of the testing container, indicating that the size was adequately large, in order to have only minor influence on the test results. Especially for the dense sand, heave of the surface was pronounced, meaning that the outermost slip line, separating the soil body at yield from the soil at rest, was easily identified.

\section{Analytical Calculation of the Bearing Capacity of a Shallow Footing}

The ultimate bearing capacity of a rough, shallow, circular foundation resting on a cohesionless material is traditionally found from the following equation, given in several textbooks:

$$
p_{f}=0.5 \gamma B N_{\gamma} s_{\gamma}+q N_{q} s_{q}, \quad s_{\gamma}=0.6, s_{q}=1.2,
$$

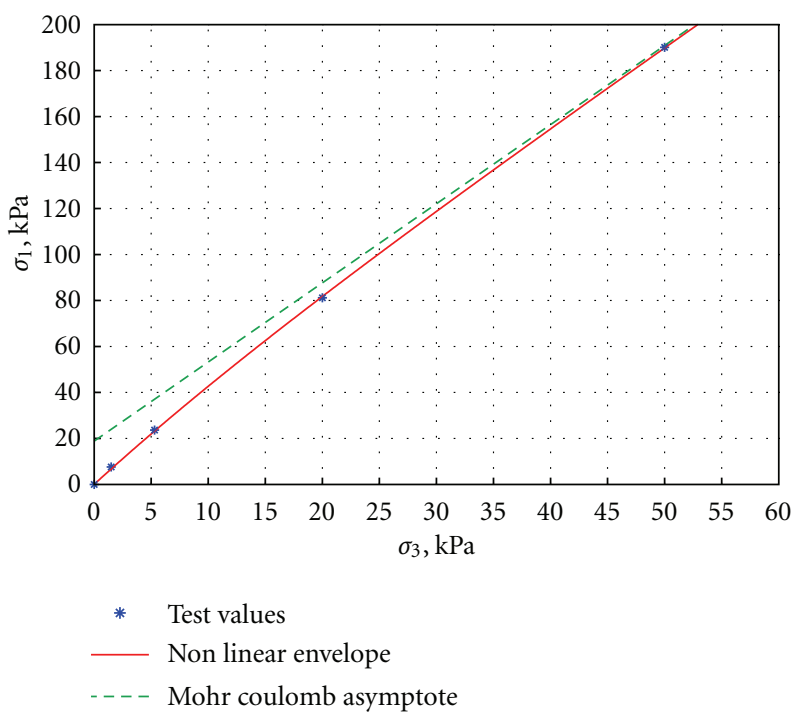

FIgure 6: Failure envelopes and test results, $D_{r}=0.84$.

where $p_{f}=$ bearing capacity pressure, $\gamma=$ effective unit weight of soil, $B=$ diameter of foundation, $N_{\gamma}$ and $N_{q}$ = bearing capacity factors which are functions of the soil friction angle $\varphi, s_{\gamma}$ and $s_{q}=$ shape factors, and $q=$ effective overburden pressure.

In the tests in this project, the footings are initially resting on the surface of the sand; that is the contribution from the overburden pressure to the ultimate load is zero at the beginning of the test, but as the load increased, the footing sinks into the ground introducing a vertical effective stress at the foundation level, which cannot be ignored, as it accounts for a significant part of the bearing capacity of the foundation. 


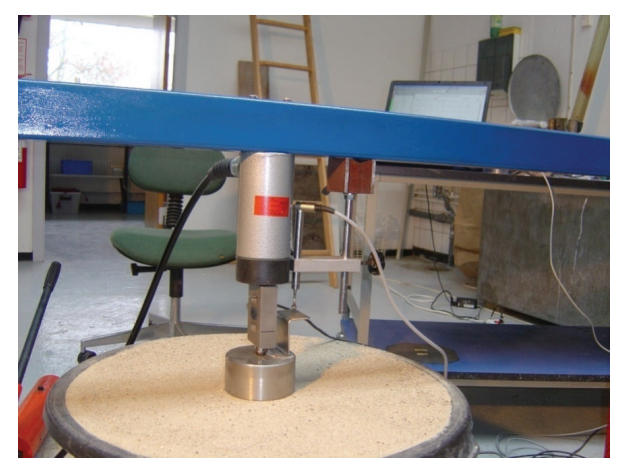

FIGURE 7: Load test arrangement.

The bearing capacity factors $N_{q}$ and $N_{\gamma}$ can be found from the below equations, the expression for $N_{q}$ presented by Reissner [27] and for $N_{\gamma}$ by Caquot and Kerisel [28]:

$$
N_{q}=\exp (\pi \tan \varphi) \tan ^{2}\left(\frac{\pi}{4}+\frac{\varphi}{2}\right), \quad N_{\gamma}=2\left(N_{q}+1\right) \tan \varphi .
$$

The overburden pressure at the foundation level can be found as $q=\delta \gamma$ where $\delta$ is the vertical displacement of the foundation and $\gamma$ the density of the sand. Inserting (16) in (15) yields the following equation for the bearing capacity:

$$
\begin{aligned}
p_{f}= & \gamma B \tan \varphi s_{\gamma}+\exp (\pi \tan \varphi) \tan ^{2}\left(\frac{\pi}{4}+\frac{\varphi}{2}\right) \\
& \times\left(\gamma B \tan \varphi s_{\gamma}+\delta \gamma s_{q}\right) .
\end{aligned}
$$

With known values of $p_{f}$ and the vertical displacement $\delta$, the value of the mobilized $\varphi$ can be found from (17); the current values of $N_{q}$ and $N_{\gamma}$ can be found from (16) and finally the contribution from the overburden pressure can be deducted from $p_{f}$ in (15) to produce the carrying capacity due to the selfweight of the soil. An example of the magnitudes of these corrections is given in Figure 8.

\section{Definition of Failure Load}

For shallow foundations, three failure modes have been described by Vesić [29], amongst others. The relevant failure modes in the present study are general shear failure and local shear failure. The general shear failure mode is expected to take place for the tests with relative density $D_{r}=0.84$ and the local shear failure mode for $D_{r}=0.59$. Typical loaddisplacement graphs for the two different modes are shown in Figure 8.

When the footing fails in general shear, there is no doubt as to the magnitude of the failure load, as the loaddisplacement curve displays a pronounced peak, as shown by the red curve in Figure 8 . When local shear occurs, the black curve in Figure 8, it becomes more difficult to point out the magnitude of the failure load, as the load continues to increase. Cerato and Lutenegger [30] suggested the failure load to be defined as the load producing a settlement of $10 \%$ of the width of the foundation, basically because this simple

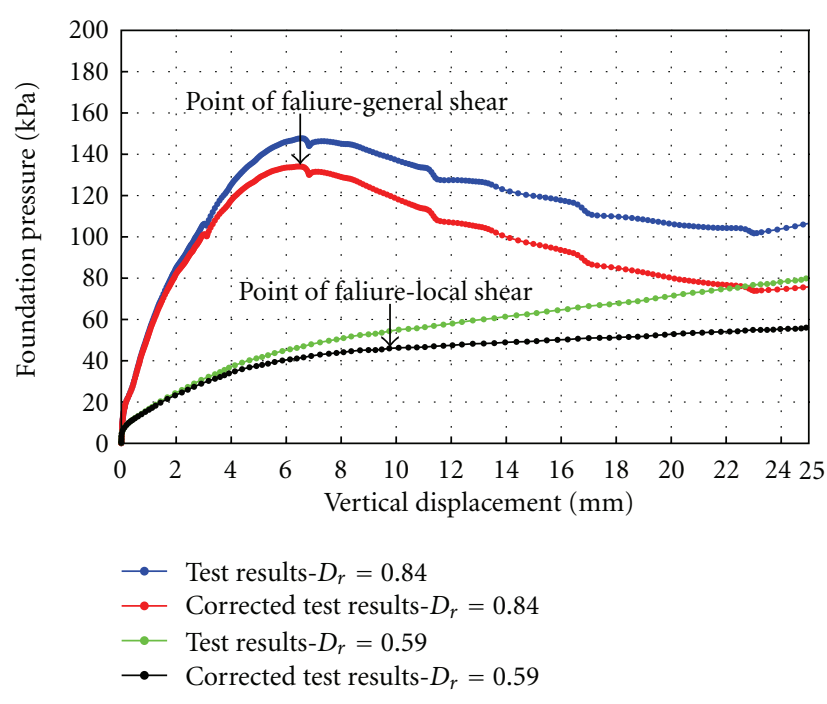

Figure 8: Definition of failure loads.

but rather arbitrary rule is easy to remember and makes the failure point trivial to identify. In Figure 8 , it is seen that the initial part of the test results representing local shear is curved and at a certain point, the curve changes into a straight line. Vesić [29] has defined the point of failure as the point, where the rate of displacement reaches its maximum value. This definition has been applied in the present study and all the test results can be seen in Table 4 and a summery together with the results from the finite element simulations is given in Table 5. It can be seen from Figure 8, that the point of failure according to Cerato and Lutenegger and according to Vesić happens to coincide, as the vertical settlement in this particular case is approximately equal to $10 \mathrm{~mm}$ which is $10 \%$ of the diameter of the model footing.

For tests where the relative density is not equal to the reference values of 0.59 or 0.84 , a modification of the measured value has been made. This modification is necessary in order to be able to calculate the average failure load for $D_{r}=0.59$ and $D_{r}=0.84$ and is carried out in the following way. From (8) it can be seen that a small change $\Delta D_{r}$ of $D_{r}$ leads to a change $\Delta \varphi$ of $\varphi$ which can be found as

$$
\Delta \varphi=3\left(Q-\ln p^{\prime}\right) \Delta D_{r},
$$

where $Q=10$ for quartz sand and $p^{\prime}$ is the mean effective stress, which can be found from the equation [31]:

$$
p^{\prime}=p_{f} \frac{1-\sin \varphi_{\text {peak }}}{4 \cos ^{2} \varphi_{\text {peak }}},
$$

where $p_{f}$ is the ultimate bearing capacity and $\varphi_{\text {peak }}$ is the friction angle at peak.

It can be seen from (18) that for a constant value of $p^{\prime}$, there is a linear relationship between $\Delta \varphi$ and $\Delta D_{r}$. In order to establish a relationship in terms of the bearing capacity between $\varphi$ and $D_{r}$, the bearing capacity of the $10 \mathrm{~cm}$ diameter footing has been found, assuming a linear Mohr Coulomb failure envelope for friction angles in the interval $34^{\circ}$ to $42^{\circ}$ and the results of this FEM analysis are given in Table 6. 
TABLE 4: Failure loads from tests.

\begin{tabular}{lcccc}
\hline Test no. & Relative density & Displacement at failure $[\mathrm{mm}]$ & Load at failure in test $[\mathrm{kPa}]$ & Modified failure load $[\mathrm{kPa}]$ \\
\hline A1 & 0.59 & 12.6 & 51 & 51 \\
A2 & 0.59 & 9.8 & 50 & 50 \\
A3 & 0.59 & 8.7 & 60 & 67 \\
A4 & 0.59 & 14.8 & 44 & 60 \\
A5 & 0.56 & 26.7 & 62 & 50 \\
A6 & 0.61 & 9.0 & 56 & 56 \\
A7 & 0.58 & 8.0 & 59 & 58 \\
A8 & 0.58 & 10.0 & 59 & 62 \\
A9 & 0.58 & 9.5 & 61 & 62 \\
A10 & 0.61 & 9.5 & 110 & 132 \\
B1 & 0.75 & 4.5 & 132 & 116 \\
B2 & 0.80 & 5.6 & 158 & 116 \\
B3 & 0.84 & 6.3 & 120 & 158 \\
B4 & 0.84 & 7.5 & 144 & 141 \\
B5 & 0.80 & 6.7 & 138 & 144 \\
B6 & 0.84 & 7.3 & 136 & 161 \\
B7 & 0.80 & 6.5 & 104 & 147 \\
B8 & 0.82 & 6.5 & 126 & 152 \\
B9 & 0.75 & 8.0 & 6.5 & \\
B10 & 0.80 & & & 147 \\
\hline
\end{tabular}

TABLE 5: Summary of results from tests and FEM calculations.

\begin{tabular}{lcccc}
\hline Relative density & $\begin{array}{c}\text { Diameter of } \\
\text { footing [mm }]\end{array}$ & $\begin{array}{c}\text { Failure load from } \\
\text { FEM analysis [kPa] }\end{array}$ & $\begin{array}{c}\text { Failure load from } \\
\text { tests [kPa] }\end{array}$ & $\begin{array}{c}\text { Standard deviation } \\
\text { of failure loads [kPa] }\end{array}$ \\
\hline 0.59 & 100 & 71 & 57 & 5.7 \\
0.84 & 100 & 151 & 148 & 13.0 \\
\hline
\end{tabular}

TABle 6: Results from linear Mohr-Coulomb analysis.

\begin{tabular}{lllllllll} 
Friction angle $\left[{ }^{\circ}\right]$ & 35 & 36 & 37 & 38 & 39 & 40 & 41 & 42 \\
\hline Failure load [kPa] & 37 & 46 & 57 & 71 & 89.0 & 111 & 141 & 174 \\
\hline
\end{tabular}

By comparing the values of the failure loads in Table 6 , with the values for the failure loads in the third column of Table 5, it can be found that the failure load for a relative density 0.59 assuming the nonlinear failure envelope is equal to the failure load at a constant friction angle of $38^{\circ}$ assuming a linear Mohr Coulomb failure envelope. For the relative density of 0.84 , the equivalent value of the constant friction angle is found by linear interpolation to be $41.3^{\circ}$. The values of $p^{\prime}$ found from (19) for the two relative densities are 11 and $23 \mathrm{kPa}$.

As an example, the modification of the result for test A7 is demonstrated. $D_{r}=0.58, p_{f}=56 \mathrm{kPa}$; that is, the equivalent $\varphi$ is in the interval $36-37^{\circ}$ and from (18);

$$
\begin{aligned}
\Delta \varphi= & 3\left(Q-\ln p^{\prime}\right) \Delta D_{r}=3(10-\ln 11) \\
& \times(0.59-0.58)=0.2^{\circ} \\
\Delta p_{f}= & \frac{57 \mathrm{kPa}-46 \mathrm{kPa}}{37^{\circ}-36^{\circ}} \cdot 0.2^{\circ}=2.2 \mathrm{kPa} .
\end{aligned}
$$

That is the modified result for A7 is $58.2 \mathrm{kPa}$, which is rounded off to $58 \mathrm{kPa}$.

\section{Conclusions}

Triaxial tests carried out on medium and dense Esbjerg sand at low stress levels show that the triaxial angle at peak depends strongly on the stress level. For confining pressures above $20 \mathrm{kPa}$, there is a reasonable match with results obtained from the equation proposed by Bolton. Because the friction angle is dependent on the confining pressure, the linear Mohr-Coulomb yield criterion is illsuited for the determination of the failure load of $1 \mathrm{~g}$ model scale footings. Therefore, on the basis of the results from the triaxial tests, a nonlinear Mohr failure criterion has been proposed and implemented in a finite element program. To overcome numerical difficulties due to the nonassociative behaviour of sand the associative flow rule is used, but with yield parameters modified with the equation given by Davis. Results from the finite element analysis of the bearing capacity of $100 \mathrm{~mm}$ diameter footings show a good agreement with results obtained from simple model-scale footing tests on medium and dense sand.

\section{Acknowledgments}

The authors wish to thank the Lida and Oskar Nielsen Foundation for a substantial, financial support. Also the 
guidance given by professor Poul V. Lade in connection with the triaxial tests is highly appreciated.

\section{References}

[1] V. M. Ponce and J. M. Bell, "Shear strength of sand at extremely low pressures," Journal of the Soil Mechanics and Foundations Division, ASCE, vol. 47, no. 4, pp. 625-637, 1971.

[2] S. Fukushima and F. Tatsuoka, "Strength and deformation characteristics of saturated sand at extremely low pressures," Soils and Foundations, vol. 24, no. 4, pp. 30-48, 1984.

[3] M. D. Bolton, "The strength and dilatancy of sands," Geotechnique, vol. 36, no. 1, pp. 65-78, 1986.

[4] B. Hansen, "Line ruptures regarded as narrow rupture zones," in Proceedings of the Brussels Conference on Earth Pressure Problems, vol. 1, pp. 39-48, Brussels, Belgium, September 1958.

[5] B. Zadroga, "Bearing capacity of shallow foundations on noncohesive soils," Journal of Geotechnical Engineering, ASCE, vol. 120, no. 11, pp. 1991-2008, 1994.

[6] E. Hoek and E. T. Brown, "Empirical strength criterion for rock masses," Journal of the Geotechnical Engineering Division, ASCE, vol. 106, no. 15715, pp. 1013-1035, 1980.

[7] H. S. Yu, "CASM: a unified state parameter model for clay and sand," International Journal for Numerical and Analytical Methods in Geomechanics, vol. 22, no. 8, pp. 621-653, 1998.

[8] G. R. McDowell and K. W. Hau, "A generalised Modified Cam clay model for clay and sand incorporating kinematic hardening and bounding surface plasticity," Granular Matter, vol. 6, no. 1, pp. 11-16, 2004.

[9] K. Krabbenhøft, "A variational principle of elastoplasticity and its application to the modeling of frictional materials," International Journal of Solids and Structures, vol. 46, no. 3-4, pp. 464-479, 2009.

[10] G. T. Houlsby, "How the dilatancy of soils affects their behaviour," in Proceedings of the 10th European Conference on Soil Mechanics and Foundation Engineering, vol. 4, pp. 11891202, Florence, Italy, May 1991.

[11] P. A. Vermeer and R. de Borst, "Non-associated plasticity for soils, concrete and rock," Heron, vol. 29, no. 3, 1984.

[12] M. T. Manzari and M. A. Nour, "Significance of soil dilatancy in slope stability analysis," Journal of Geotechnical and Geoenvironmental Engineering, ASCE, vol. 126, no. 1, pp. 75-80, 2000.

[13] A. Drescher and E. Detournay, "Limit load in translational failure mechanisms for associative and non-associative materials," Geotechnique, vol. 43, no. 3, pp. 443-456, 1993.

[14] E. H. Davis, "Theories of plasticity and the failure of soil masses," in Soil Mechanics, Selected Topics, I. K. Lee, Ed., pp. 341-380, Butterworths, London, UK, 1968.

[15] D. H. Cornforth, "Prediction of drained strength of sands from relative density measurements," in Evaluation of Relative Density and Its Role in Geotechnical Projects Involving Cohesionless Soils, pp. 281-303, American Society for Testing and Materials, 1973.

[16] V. F. B. de Mello, "Reflections on design decisions of practical significance to embankment dams - 17th Rankine lecture," Geotechnique, vol. 27, no. 3, pp. 281-355, 1977.

[17] J. A. Charles and K. S. Watts, "The influence of confining pressure on the shear strength of compacted rockfill," Geotechnique, vol. 30, no. 4, pp. 353-367, 1980.
[18] I. F. Collins, C. I. M. Gunn, M. J. Pender, and W. Yan, "Slope stability analyses for materials with a non-linear failure envelope," International Journal for Numerical \& Analytical Methods in Geomechanics, vol. 12, no. 5, pp. 533-550, 1988.

[19] P. Simonini, "Influence of relative density and stress level on the bearing capacity of sands," International Journal for Numerical \& Analytical Methods in Geomechanics, vol. 17, no. 12, pp. 871-890, 1993.

[20] R. Baker, "Nonlinear Mohr envelopes based on triaxial data," Journal of Geotechnical and Geoenvironmental Engineering, vol. 130, no. 5, pp. 498-506, 2004.

[21] R. Baker and R. Awidat, "Optimal choice of non-linear Mohr envelopes," in Proceedings of the 12th Asian Regional Conference on Soil Mechanics and Geotechnical Engineering, pp. 1-5, Bombay, India, 2007.

[22] J. Clausen and L. Damkilde, "An exact implementation of the Hoek-Brown criterion for elasto-plastic finite element calculations," International Journal of Rock Mechanics and Mining Sciences, vol. 45, no. 6, pp. 831-847, 2008.

[23] M. S. A. Siddiquee, T. Tanaka, F. Tatsuoka, K. Tani, and T. Morimoto, "Numerical simulation of bearing capacity characteristics of strip footing on sand," Soils and Foundations, vol. 39, no. 4, pp. 93-109, 1999.

[24] F. Tatsuoka, M. Okahara, T. Tanaka, K. Tani, T. Morimoto, and S. A. Siddiquee, "Progressive failure and particle effect in bearing capacity of a footing on sand," in Proceedings of the ASCE Geotechnical Engineering Congress, Boulder, vol. 27, pp. 788-802, 1991.

[25] T. Kimura, O. Kusakabe, and K. Saitoh, "Geotechnical model tests of bearing capacity problems in a centrifuge," Geotechnique, vol. 35, no. 1, pp. 33-45, 1985.

[26] O. Kusakabe, Foundations, Chapter 6 of Geotechnical Centrifuge Technology, Blackie Academic and Professional, London, UK, 1995.

[27] H. Reissner, "Zum erddruckproblem," in Proceedings of the 1st International Congress of Applied Mechanics, pp. 295-311, Delft, The Netherlands, 1924.

[28] A. Caquot and J. Kerisel, "Sur le terme de surface dans le calcul des foundations en milieu pulverulent," in Proceedings of the 3 rd International Conference on Soil Mechanics and Foundation Engineering, vol. 1, pp. 336-337, Zürich, Switzerland, 1953.

[29] A. S. Vesić, "Analysis of ultimate loads of shallow foundations," Journal of the Soil Mechanics and Foundations Division, ASCE, vol. 99, no. 1, pp. 45-73, 1973.

[30] A. B. Cerato and A. J. Lutenegger, "Scale effects of shallow foundation bearing capacity on granular material," Journal of Geotechnical and Geoenvironmental Engineering, ASCE, vol. 133, no. 10, pp. 1192-1202, 2007.

[31] S. W. Perkins and C. R. Madson, "Bearing capacity of shallow foundations on sand: a relative density approach," Journal of Geotechnical and Geoenvironmental Engineering, ASCE, vol. 126, no. 6, pp. 521-530, 2000. 

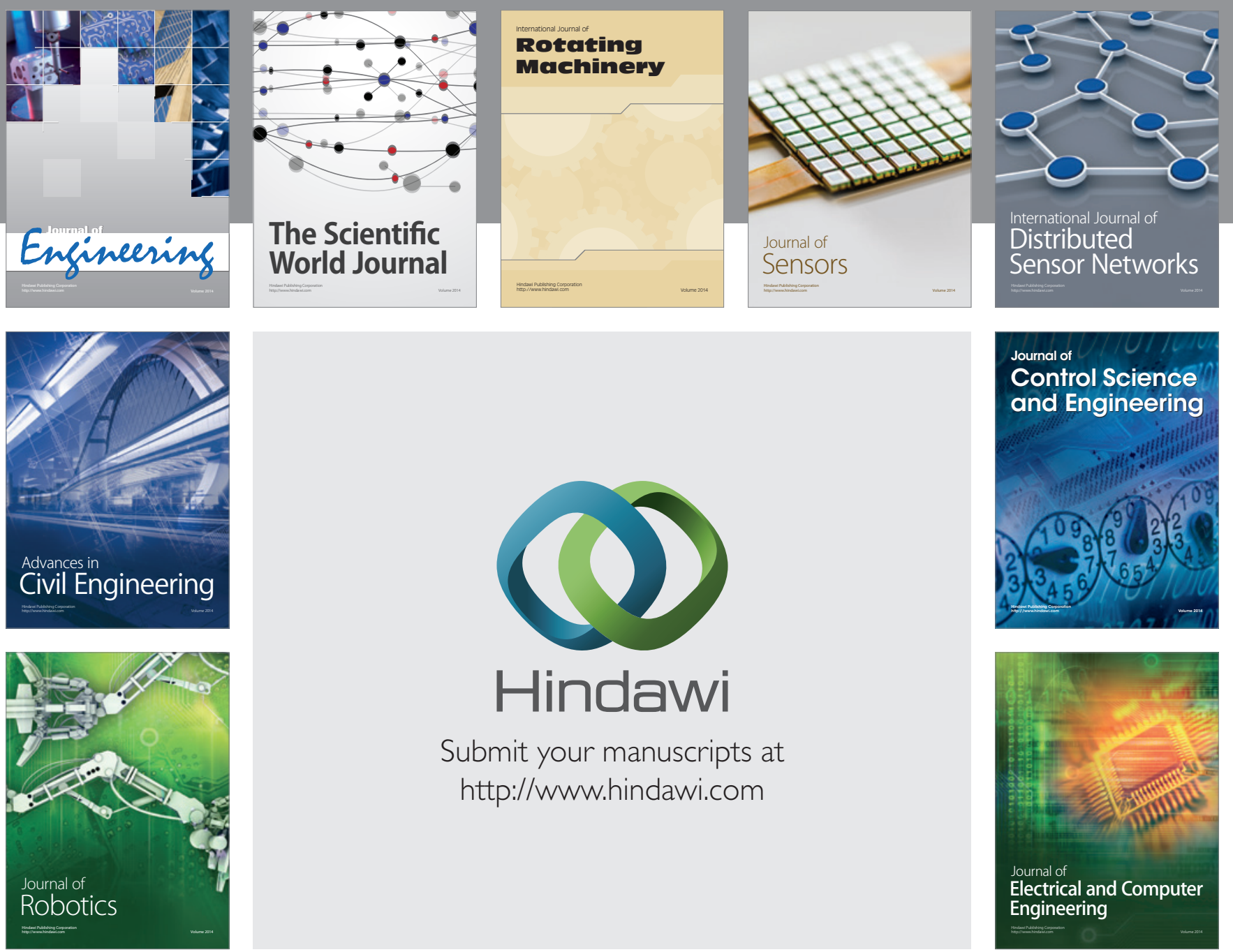

Submit your manuscripts at

http://www.hindawi.com
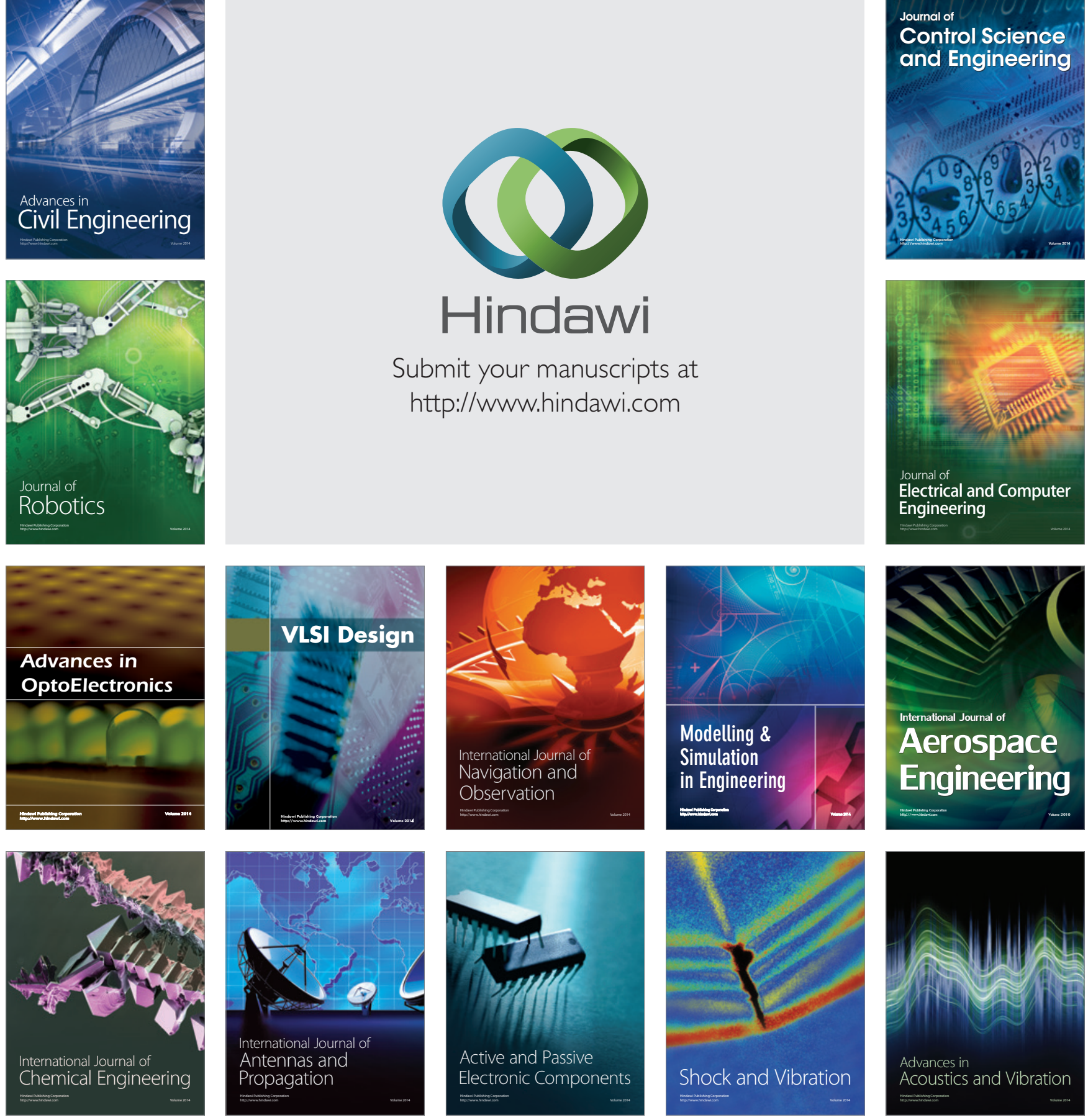